\title{
Effect of Temperature on the AlGaAs/GaAs Tandem Solar Cell for Concentrator Photovoltaic Performances
}

\author{
Hemmani Abderrahmane*, B. Dennai†, H. Khachab, A. Helmaoui \\ Laboratory of Semiconductor Devices Physics, Matter sciences Department, Faculty of Exact Sciences, TAHRI Mo- \\ hammed University of Béchar, P.O. Box 417, Bechar, Algeria
}

(Received 27 November 2015; revised manuscript received 05 March 2016; published online 15 March 2016)

\begin{abstract}
Multijunction solar cells for concentrator photovoltaic (CPV) systems have attracted increasing attention in recent years for their very high conversion efficiencies. But there is a problem in this type of solar cells (CPV) is to increase the temperature if it has been augmenting the concentration ratio. In this paper, we studied the effect of the concentration photovoltaic in a high-efficiency double-junction devices solar cell on temperature solar cell and its impact on the photocurrent, the efficiency and open circuit voltage. In this study, the top cell is made of AlGaAs $(1.73 \mathrm{eV})$ while the bottom cell is made of GaAs $(1.42 \mathrm{eV})$ between them a tunnel junction.
\end{abstract}

Keywords Tandem solar cell, Concentrator, Temperature, AlGaAs/GaAs, Performances.

PACS numbers: 88.40.jm

\section{INTRODUCTION}

Photovoltaic is accepted as a promising technology that directly takes advantage of our planet's ultimate source of power, the sun. When exposed to light, solar cells are capable of producing electricity without any harmful effect to the environment or devices. Therefore, they can generate power for many years (at least 20 years) while requiring only minimal maintenance and operational costs. Currently the wide-spread use of photovoltaic over other energy sources is impeded by the relatively high cost and low efficiency of solar cells [1].

Multijunction solar cells built from III-V semiconductors are being evaluated globally in CPV systems designed to supplement electricity generation for utility companies. The high efficiency of III-V multijunction concentrator cells, with demonstrated efficiency over $40 \%$ since 2006 [10], strongly reduces the cost of CPV systems, and makes III-V multijunction cells the technology of choice for most concentrator systems today.

It should be considered that the temperature of the solar cell will increase dramatically under light concentrating operation which will significantly influence the performance of the cell. The conversion efficiency and the open-circuit voltage $(V o c)$ of solar cells will decrease with increasing temperature [2, 3]. Several researchers have studied the temperature dependence of many kinds of solar cells $[4,5]$ but has proved that the temperature range was tight. Therefore, it is useful to study the temperature characteristics for tandem solar cell in detail, the temperature range should be wider because solar cells combination of concentrations.

In this paper, we propose a two-junction solar cell device having AlGaAs (1.73 eV) as a top cell and GaAs $(1.42 \mathrm{eV})$ as a bottom cell. The two cells are connected back to back and separated by tunnel junction GaAs [6] the reported for purpose was to studied the influence of temperature on the solar cell parameters (photocurrent, open circuit voltage and efficiency) in a fairly wide range of concentration levels (1 to100 sun).

\section{MODEL DISCRIPTION}

\subsection{Device Modeling}

The structural diagram of the fabricated AlGaAs/GaAs between there tunnel junction whith concentrator solar cells are shown in Figure 1. The epilayers of the fabricated samples were grown by MOCVD technique. The cell area is $10 \mathrm{~mm} \times 10 \mathrm{~mm}$. The main post-growth technology of tandem cells includes photolithography, evaporation, metallization and selecting etching. The front grids contact was evaporater using $\mathrm{Ti} / \mathrm{Pt} / \mathrm{Au}$ and the back contact was formed of $\mathrm{Ti} / \mathrm{Pd} / \mathrm{Ag}$ using evaporation.

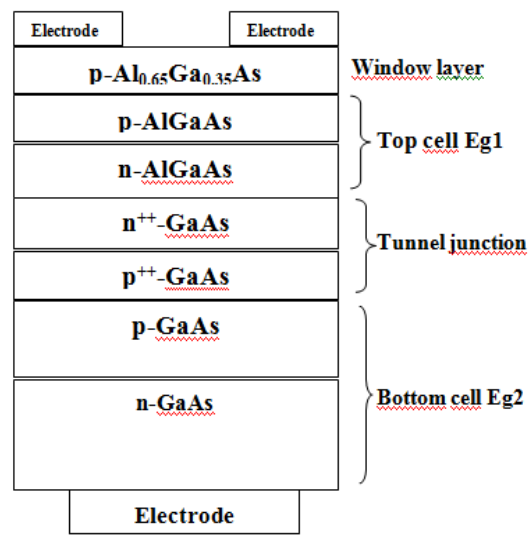

Fig. 1 - The structure of the multijunction

The base parameters used for different structures adopted from some standard references are shown in Table 1[11], [12].

\subsection{Analytical Model}

In this work, calculations were all performed under (1 to 100 sun) AM1.5 illumination and a temperature of

\footnotetext{
*hemani1973@yahoo.fr

†deennai_benmoussa@yahoo.com
} 
$300 \mathrm{~K}$ using the one diode ideal model, and for convenience, several simplifying assumptions were made,

Table 1 - The parameters of tandem solar cell

\begin{tabular}{|l|l|l|}
\hline \multirow{2}{*}{ Parameters } & \multicolumn{2}{|c|}{ Values } \\
\cline { 2 - 3 } & $\begin{array}{c}\text { Top cell } \\
\text { AlGaAs }\end{array}$ & $\begin{array}{c}\text { Bottom } \\
\text { Cell GaAs }\end{array}$ \\
\hline Band Gap $(\mathrm{eV})$ & 1.73 & 1.43 \\
\hline Doping concentrations Na $\left(\mathrm{cm}^{-3}\right)$ & $2 \times 10^{17}$ & $2 \times 10^{17}$ \\
\hline Doping concentrations Nd $\left(\mathrm{cm}^{-3}\right)$ & $2 \times 10^{17}$ & $2 \times 10^{17}$ \\
\hline Intrinsic density $n_{i}\left(\mathrm{~cm}^{-3}\right)$ & $2 \times 10^{3}$ & $2.1 \times 10^{6}$ \\
\hline Thickness the region $P X_{j}(\mathrm{~cm})$ & $0.8 \times 10^{-4}$ & $1 \times 10^{-4}$ \\
\hline Thickness the region $P H(\mathrm{~cm})$ & $1 \times 10^{-4}$ & $2.5 \times 10^{-4}$ \\
\hline $\begin{array}{l}\text { The recombination velocity front } \\
\text { surface } S_{n}\left(\mathrm{~cm}^{2} \mathrm{~s}^{-1}\right)\end{array}$ & $1 \times 10^{4}$ & $1 \times 10^{4}$ \\
\hline $\begin{array}{l}\text { The recombination velocity back } \\
\text { surface } S_{p}\left(\mathrm{~cm}^{2} \mathrm{~s}^{-1}\right)\end{array}$ & $1 \times 10^{4}$ & $1 \times 10^{4}$ \\
\hline
\end{tabular}

including no series resistance losses, no reflection losses and contact shadowing.

The total the photo current density from single cells under illumination is given by:

$$
j_{p h}=j_{n}+j_{p}+j_{w}
$$

where $j_{n}$ the photo current density in the emitter region is expressed by:

$$
J_{n}=-\left.e D_{n} \frac{d \Delta n}{d x}\right|_{x=w_{e}+w}
$$

where $\Delta n$ is the excess electrons concentration in $P$ layer. $D_{n}$ the diffusion constant for electrons, With

$$
\begin{aligned}
& J_{n}=\frac{q F(1-R) \alpha L_{n}}{\alpha^{2} L_{n}^{2}-1} \times \\
& \times\left[\frac{\left(\frac{S_{n} L_{n}}{D_{n}}+\alpha L_{n}\right)-\exp \left(-\alpha x_{j}\right)\left(\frac{S_{n} L_{n}}{D_{n}} \cosh \frac{x_{j}}{L_{n}}+\sinh \frac{x_{j}}{L_{n}}\right)}{\frac{S_{n} L_{n}}{D_{n}} \sinh \frac{x_{j}}{L_{n}}+\cosh \frac{x_{j}}{L_{n}}}-\right. \\
& \left.-\alpha L_{n} \exp \left(-\alpha x_{j}\right)\right]
\end{aligned}
$$

$X_{j}$ - the thickness of the region $P$

$\alpha-$ absorption coefficient.

$F$ - Incident photon flux at surface

$S_{n}$ - the recombination velocity front surface

$D_{n}$ - the diffusion constant for electrons

$\tau_{n}$ - the electrons lifetime.

$R$ - coefficient reflection.

$J_{p}$ The photo current density in the base region is expressed by:

$$
J_{p}=-\left.e D_{p} \frac{d \Delta p}{d x}\right|_{x=w_{e 1}}
$$

$\Delta p$ is the excess hole concentration, $D_{p}$ the diffusion constant for holes and $\tau_{p}$ the holes lifetime.

With $L_{p}^{2}=D_{p} \tau_{p}$

$$
\begin{aligned}
& J_{p}(\lambda)=\frac{q F(1-R) \alpha L_{p}}{\alpha^{2} L_{p}^{2}-1} \exp \left(-\alpha\left(x_{j}+w\right)\right) \\
& \times\left[\alpha L_{p}-\frac{\frac{S_{p} L_{p}}{D_{p}}\left[\cosh \frac{H}{L_{p}}-\exp (-\alpha H)\right]+\sinh \frac{H}{L_{p}}+\alpha L_{p} \exp (-\alpha H)}{\frac{S_{p} L_{p}}{D_{p}} \sinh \frac{H}{L_{p}}+\cosh \frac{H}{L_{p}}}\right]
\end{aligned}
$$

$H$ - the thickness of the region $N$

$S_{p}$ - the recombination velocity back surface

$D_{p}$ - the diffusion constant for electrons

$\tau_{p}$ - the electrons lifetime

The photo current density in space charge layer $n-p$ is expressed by [1]:

$$
J_{w}(\lambda)=q F(1-R) \exp \left(-\alpha x_{j}\right)[1-\exp (-\alpha \times w)](2.6)
$$

Where $W$ is the space charge layer $n-p$ thickness.

The open circuit voltage is given by:

$$
V_{C O}=\frac{k T}{q} \cdot \log \left\{1+\frac{J_{p h}}{J_{0}}\right\}
$$

\subsection{PV Characteristic}

The power supplied to the external circuit by the solar cell under illumination depends on the load resistor (external resistor placed across the cell). This power is maximum for an operating point $\left(P_{m}, J_{m}\right.$ and $\left.V_{m}\right)$ of the current-voltage curve. To this point we can write:

After approximations

$$
\begin{gathered}
V_{m p}=V_{C O}-\frac{K \cdot T}{q} \cdot \log \left(1+\frac{q \cdot V_{m p}}{K \cdot T}\right) \\
J_{m p}=\left[J_{p h}+J_{0}\left(e^{\frac{q V_{m p}}{K T}}-1\right)\right]
\end{gathered}
$$

The cell conversion efficiency is usually taken to be:

$$
\eta=\frac{P_{\max }}{P_{i n}}=\frac{J_{m} \cdot V_{m}}{P_{i n}}
$$

$P_{i n}$ is the total incident solar power.

For maximum efficiency, each cell should be operated at its optimal J-V parameters, which are not necessarily equal for each cell. If they are different, the total current through the solar cell is the lowest of the two. By approximation, it results in the same relationship for the shortcircuit current of the multi-junction mode tandem solar cell:

$$
J=\min \left(J_{m k}\right)
$$

An operating voltage $V_{m}$ and power output will be obtained:

$$
P_{m}=V_{m} \cdot \min \left(J_{1-2}\right)
$$

Where:

$$
V_{m}=V_{1}+V_{2}-V_{T J}
$$


With :

$V_{1}$ - voltage top solar cell.

$V_{2}$ - voltage bottom solar cell.

$V_{T J}$ - voltage tunnel junction

$$
\eta_{t}=\frac{P_{m t}}{P_{i n}}
$$

\section{RESULTS AND DISCUSSION}

In order to determine the cell temperature, Solving numerically allows us to obtain the optimal process temperature according to the solar concentration ratio (Figure 2)

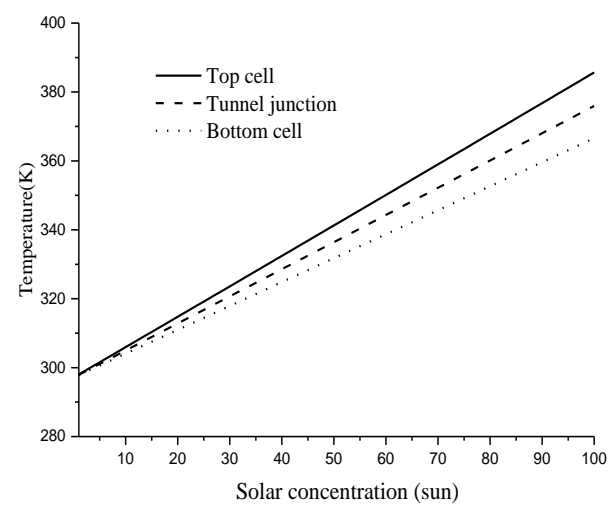

Fig. 2 - Solar concentration dependence of the temperature

Note that there is a temperature increase in the device but the largest increase in the upper top cell because it is directly exposed to light.

\subsection{Effect of Temperature on the Optimized Tan- dem Solar Cell}

After calibration of the AlGaAs/GaAs solar cell, the effect of temperature on the GaInP/GaAs tandem solar cell is investigated with two components: Top cell (AlGaAs) and Bottom cell (GaAs). The operating temperature of the cells was varied from $295 \mathrm{~K}$ to $400 \mathrm{~K}$. The simulation results are shown in Figures 3, 4 and 5 .

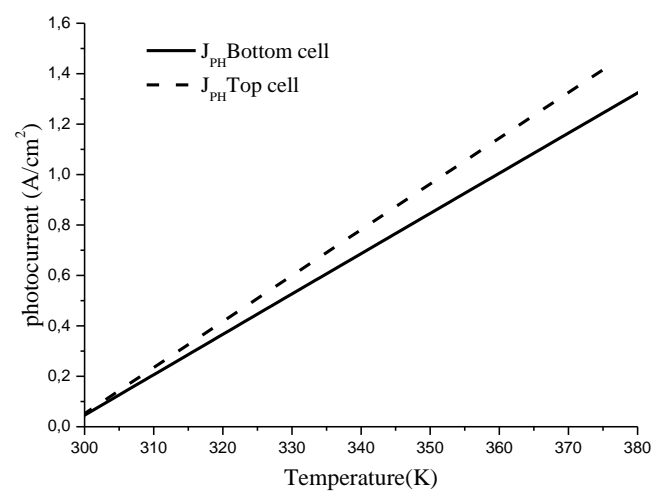

Fig. 3 - Temperature dependence of the photocurrent

Figure 3 show a little of instability in short photocurrent high values of temperature for both cells (up down) .But we note that the photoelectric cell is greater than before the photocurrent the bottom cell.

Figure 4 show a Due to the augmentation of the darkness current density $J_{o}$ (reverse saturation current density) of the cell, the open circuit voltage decreases

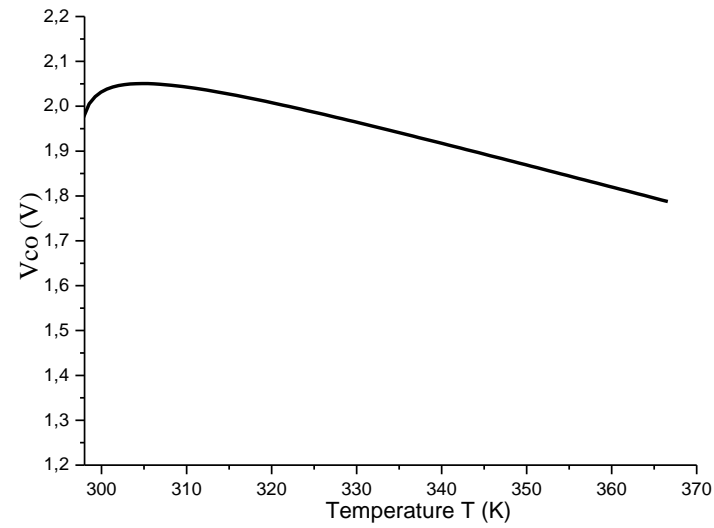

Fig. 4 - Temperature dependence of the open circuit voltage

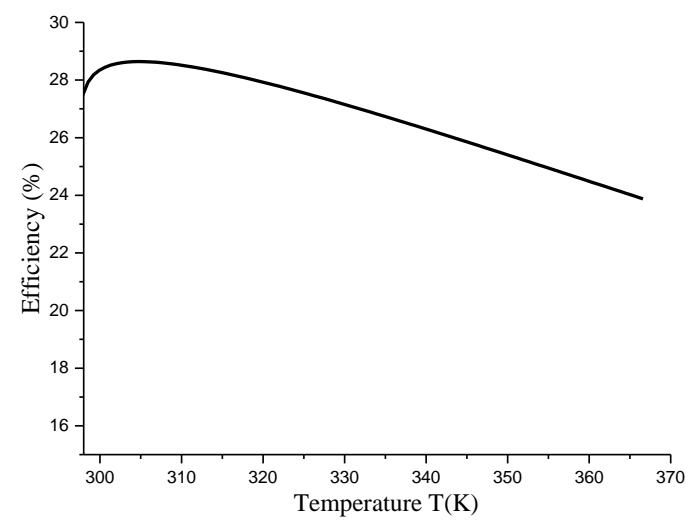

Fig. 5 - Temperature dependence of the efficiency

linearly with the increase of temperature $T>300 \mathrm{~K}$. This is true for the top cell, bottom cell and the monolithic tandem cell [7]

Figure 5 shows the efficiency of the solar cell when the concentration is increased. The temperature is set to $310 \mathrm{~K}$. It shows the typical shape of this type of curves, although the maximum in efficiency is in our simulation at a concentration of around 20 suns, which is higher than typical values observed experimentally.

\section{CONCLUSIONS}

In this work, we studied the behavior of AlGaAs/GaAs Tandem solar cell under concentration. The electrical properties of the cells are studied for a variant concentration in the range between 1 and 100 sun. We have show that the temperature increase causes reduction of open-circuit voltage, and conversion the efficiency of the cell.

For the tandem cell, the change in short-circuit with the current temperature is remarkable in the two cells. We can see that the tandem cell performance depends on characteristics of the bottom cell when the cell temperature is increasing 


\section{REFERENCES}

1. M.A. Green, Third generation photovoltics (Berlin: Springer: 2005).

2. S.M. Sze, Physics of semiconductor devices. 2nd ed. (New York: John Wiley\&Sons: 1969)

3. A.L. Fahrenbruch, R.H. Bube, Fundamentals of solar cells (Academic Press Inc.: 1983).

4. M.Y. Feteha, G.M. Eldallal, Renew Energ. 28 No 7, 1097 (2003).

5. K. Nishioka, T. Takamoto, T. Agui, Sol. Energ. Mater. Sol. C. 90, 57 (2006).

6. Benmoussa Dennai,

H. Ben Slimane,

A. Helmaoui,

J. Nano-Electron. Phys. 6 No 4, 04001 (2014).

7. C. John, C. Fan, Sol. Cells 17, 309 (1986).

8. G.B. Stephanovich, Thin films in the Optics and Electronics (Kharkiv: NNC KhFTI: 2003).

9. Hector Cotal, et al., Rev. Energ. Environmen. Sci. 2, 174 (2009).

10. M.R. Brozel, G.E. Stillman, Properties of Gallium Arsenide (INSPEC: 1996)

11. H.A. Zarem, J.A. Lebens, K.B. Nordstrom, P.C. Sercel, S. Sanders, L.E. Eng, A. Yariv, K.J. Vahala, Appl. Phys. Lett. 55, 2622 (1989). 